\title{
Dual Pricing of Periodicals
}

The pervasiveness and nature of dual pricing of periodicals (different subscription price structures for institutions and individuals) is explored, employing a stratified sample of 180 American titles for a span of ten years (1966-75). Initiated at least as early as the mid1950s, approximately 15 percent of all titles sampled now stipulate two subscription rates. The extent of such a phenomenon on periodical budgets is magnified by the fact that the disparity between the two subscription rates is increasing, and the mean annual institutional rate is rising at a significantly faster rate than the mean price assessed to individual subscribers.

C periodicals has been in existence for several years. It cannot, however, be said that the talk has in any way been substantive in nature regarding the subject. Still there has been at least an awareness that publishers of periodicals quite frequently charge a higher rate for institutional subscribers than for individual subscribers. There also has been the expressed uneasiness regarding the trend toward higher institutional rates which only seemed to fuel the effect of inflation on the cost of library materials. But as with other facts of life there seemed to be the typical resignation to the increased costs via this double pricing scheme. At the time of this investigation (early 1976) the literature was void of material pertaining to dual pricing. Only recently has a paper appeared which confronts the problem of pricing discrimination against libraries: Herbert S. White's "Publishers, Libraries, and Costs of Journal Subscriptions in Times of Funding Retrenchment."1

The purpose of this investigation has

Glenn R. Wittig is a doctoral student, School of Library Science, University of Michigan, Ann Arbor. been to explore the nature of the phenomenon of dual pricing of periodicals. As an initial study of the subject, the investigator has been interested primarily in determining the present situation. Since so little information was known beforehand, no hypotheses were tested. Various questions, however, were raised, such as:

1. What percentage of American periodicals had a double subscription price structure (i.e., one subscription rate for individuals and another for institutions, particularly libraries )?

2. What was the earliest incidence of dual pricing?

3. Is there evidence of a growing disparity between the two rates?

These questions provided the framework for this investigation.

\section{METHODOLOGY}

A study of the cost of American periodicals and serial services appears annually in Library Journal. This survey of periodical costs is divided into twenty-four subject categories and one composite index. The categories used are: Agriculture; Business and Economics; Chemistry and Physics; Children's Periodicals; Education; Engineering; Fine 
and Applied Arts; General Interest Periodicals; History; Home Economics; Industrial Arts; Journalism and Communications; Labor and Industrial Relations; Law; Library Science; Literature and Language; Mathematics, Botany, Geology, and General Science; Medicine; Philosophy and Religion; Physical Education and Recreation; Political Science; Psychology; Sociology and Anthropology; and Zoology. The rubric for the composite index is: U.S. Periodicals. The $L J$ annual survey, however, cites only a single average price per category; a distinction in subscription rates is not made. In 1975, 3,075 periodical titles were included in the survey.

Since it was not possible for the present investigator to conduct a survey similar in scope to that conducted annually by $L J$, the following alternative approach was devised. The universe of titles chosen were those indexed in the ten well-known $\mathrm{H}$. W. Wilson Company indexes: Applied Science \& Technology Index; Art Index; Biological \& Agricultural Index; Business Periodicals Index; Education Index; Humanities Index; Index to Legal Periodicals; Library Literature; Readers' Guide to Periodical Literature; and Social Science Index. The subject distinctions of the ten indexes served as the subject parameters for this investigation. No further division into smaller subject groupings was attempted. A sample of 200 American titles, twenty from each of the above named indexes, was randomly selected.

To provide as much comparability as possible with the $L J$ studies, the definition criteria used there were accepted for this study as well. Each title first had to meet the definition of a periodical as formally established by the American National Standards Institute. ${ }^{2}$ ANSI's statement defines a periodical as "a publication which constitutes one issue in a continuous series under the same title, published more than twice a year over an indefinite period, individ- ual issues in the series being numbered consecutively or each issue being dated. Newspapers are excluded." Serial services also were excluded from this study. The periodical was to be published in the United States, and, quite obviously, it had to be priced.

It was further determined to conduct this survey for a ten-year span from 1966 to 1975 . It was assumed that the initiation of dual pricing in periodicals was a comparatively recent phenomenon and that a span of ten years would quite adequately cover the period prior to, and including, the present situation. It likewise was assumed that such a span of coverage would have been sufficient to reveal any strong trends, particularly because of the higher rates of inflation experienced during the past several years. Newer periodicals not in existence for the full decade were retained in the sample. On the other hand, various titles not having a continuous publication history during the past decade were not retained as part of the sample. Whenever a title appeared in the sample more than once (having been drawn from different source indexes), the decision as to which would be retained was made by random selection. A new title then was selected to replace the deleted duplicate.

Subscription prices by necessity were derived from the source. Peculiarities in the bibliographical-acquisition tools available to librarians did not permit the extraction of subscription rates with any degree of confidence. Subscription information in such well-known sources as Ulrich's International Periodicals Directory and the Standard Periodical Directory were invariably not current. No other single source provided accurate annual subscription prices or any clues to the existence of dual price structures. Thus annual volumes of the periodicals had to be examined. Subscription rates were taken from an issue late in the year or volume but not from the last is- 
sue. It was assumed in this regard that a price (particularly a price change) listed in the last issue was more an indication of the rate for the new year than a true reflection of the rate for the year almost past.

For a number of reasons which made it difficult to derive subscription rates to legal periodicals, even from the source, this group was eliminated from the study. As a result, a net total of 180 periodicals from nine of the ten Wilson indexes comprised the sample used for this study.

\section{ResUlts}

The percentage of periodicals having a dual price structure rose from a mere 4 percent in 1966 to a rather substantial and deceptively influential 15 percent ten years later (see Table 1). The rates of increase rose most sharply during the late 1960s (from 1968 to 1970), again between 1971 and 1972, and once more from 1973 to 1974 , revealing a step-wise pattern.

Applied science, biological-agricultur$\mathrm{al}$, and education periodicals were free of the dual price phenomenon in the early years of the survey; and the former two, along with library periodicals, remained less than 15 percent by 1975 . The subject category of periodicals which manifested the strongest characteristic of double pricing was social science. Seven of the twenty periodicals

TABLE 1

Number and Percent Periodicals Stipulating a Dual Price Structure

\begin{tabular}{ccrr}
\hline \hline Date & Population & N & Percent \\
\hline 1966 & 166 & 7 & 4.22 \\
1967 & 166 & 7 & 4.22 \\
1968 & 169 & 9 & 5.33 \\
1969 & 170 & 12 & 7.06 \\
1970 & 173 & 15 & 8.67 \\
1971 & 175 & 15 & 8.57 \\
1972 & 178 & 20 & 11.24 \\
1973 & 179 & 21 & 11.73 \\
1974 & 180 & 26 & 14.44 \\
1975 & 180 & 27 & 15.00 \\
\hline
\end{tabular}

sampled in that index category stipulated a double price structure. Conversely, the periodicals sampled from Readers' Guide remained free of any double price structure throughout the time span of the survey.

Periodicals published no more than four times a year are the most frequently double priced type of publication. On the other hand, weekly and bi-weekly publications are the least affected by such a pricing policy. The results of a chi square test on this distribution of number of issues per year/volume was significant at the 99 percent confidence level. The frequency distribution obtained for periodicals with two subscription rates was significantly different from what would have been expected solely by chance (see Table 2 ).

Quite surprisingly, especially in a time of such high inflation, it likewise was discovered that eight periodicals (4.5 percent) experienced no price change whatsoever during the past decade. Spread throughout five of the nine indexes, the eight periodicals were: the New England Quarterly and the Texas Quarterly from the Humanities Index; American Imago and the Clearing House from Readers' Guide; the American Federationist and the International Monetary Fund Staff Papers covered by the Business Periodicals Index; the Oberlin College Allen Memorial Art Museum Bulletin from the Art Index; and Food Engineering covered by the Applied Science of Technology Index.

TABLE 2

Distribution of Periodicals by Frequency of Publication

\begin{tabular}{lcrrrr}
\hline \hline $\begin{array}{c}\text { Price } \\
\text { Structure }\end{array}$ & $2-4$ & \multicolumn{5}{c}{ Number Issues } & Per Year \\
& & & $8-12$ & $20-52$ & Total \\
\hline One & 65 & 19 & 51 & 18 & 153 \\
Two & 21 & 1 & 5 & 0 & 27 \\
Both & 86 & 20 & 56 & 18 & 180 \\
\hline
\end{tabular}

Chi square $=12.347$

Critical value ( 3 degrees of freedom, 0.01 level of confidence $)=11.341$ 
One of these-the International Monetary Fund Staff Papers-even had dual subscription rates.

An assumption was stated above under "Methodology" that the initiation of dual pricing of periodicals was a very recent phenomenon. The investigation has, however, proved this to be false. More than 4 percent of the sample in 1966 already were stipulating different subscription rates for individuals and libraries. A check of those seven items revealed that dual subscription pricing began at least as early as the mid-1950s. In 1956 the Philosophical Review (a quarterly), for example, began charging $\$ 6.00$ for library subscriptions and $\$ 3.00$ for individual subscriptions. The Business History Review (another quarterly) apparently had a dual structure in effect as early as 1955 but did not enumerate the specifics in its masthead until 1957. The remaining five periodicals initiated their dual subscription structures in 1961, 1963, 1965, and 1966 respectively.

A third area of interest in this investigation pertained to the possible effect dual pricing was having on periodical subscription rates and, in turn, on library periodical budgets. The answer given depends as much on the perspective taken as it does on the size and nature of individual libraries.

The effect on the annual mean subscription price for the entire sample $(\mathrm{N}=180)$ is very slight. When averaged in among all price rates, the difference is seen as only a few cents more per title per year (see Figure 1). However, when the periodicals having a dual price structure $(\mathrm{N}=27)$ are considered as a group separated from the larger sample, the annual price increase from 1968 to 1975 shows a very marked difference, significant at the 95 percent level of confidence as measured by the MannWhitney test (see Figure 2). The mean incremental difference in 1975 among these journals was almost seven dollars per title. The institutional subscription rates are rising at a significantly faster pace than are the rates for individuals and, consequently, can have a very marked impact on periodical budgets.

\section{Discussion}

The evidence presented thus far in this paper indicates that (1) the dual price phenomenon has been in existence far longer than was initially assumed and that (2) the number (percentage) of periodicals using such a rate structure is increasing. While the percentage of periodicals currently operating on a two-tier price structure (15 percent) is still comparatively small so as not to effect a marked change in the mean anual subscription prices (cf., Figure 1), evidence derived from the investigation reveals that (1) periodicals included in the Social Science Index are most frequently affected by the double pricing scheme and that (2) periodicals in education and applied science and technology show the greatest disparity between the two subscription rates.

These results could have marked effects on libraries with numerous subscriptions to periodicals in these subject areas, and the more so the larger the number of subscriptions. The degree of sampling variability, however, indicates that the number of dually priced periodicals (15 percent) could actually range between 9.8 and 20.2 percent 95 percent of the time. Consequently, the ability to assert the true strength of the inevitable trend toward more double pricing by publishers is considerably lessened but by no means negated.

The data seem to indicate that given the general state of the economy, more than a two-tier subscription rate is creating the rising spiral in periodical costs to libraries. Yet when the small portion of periodicals having two subscription rates is viewed as a unit, a different, more troubling, picture is obtained. There is definite evidence, as confirmed 


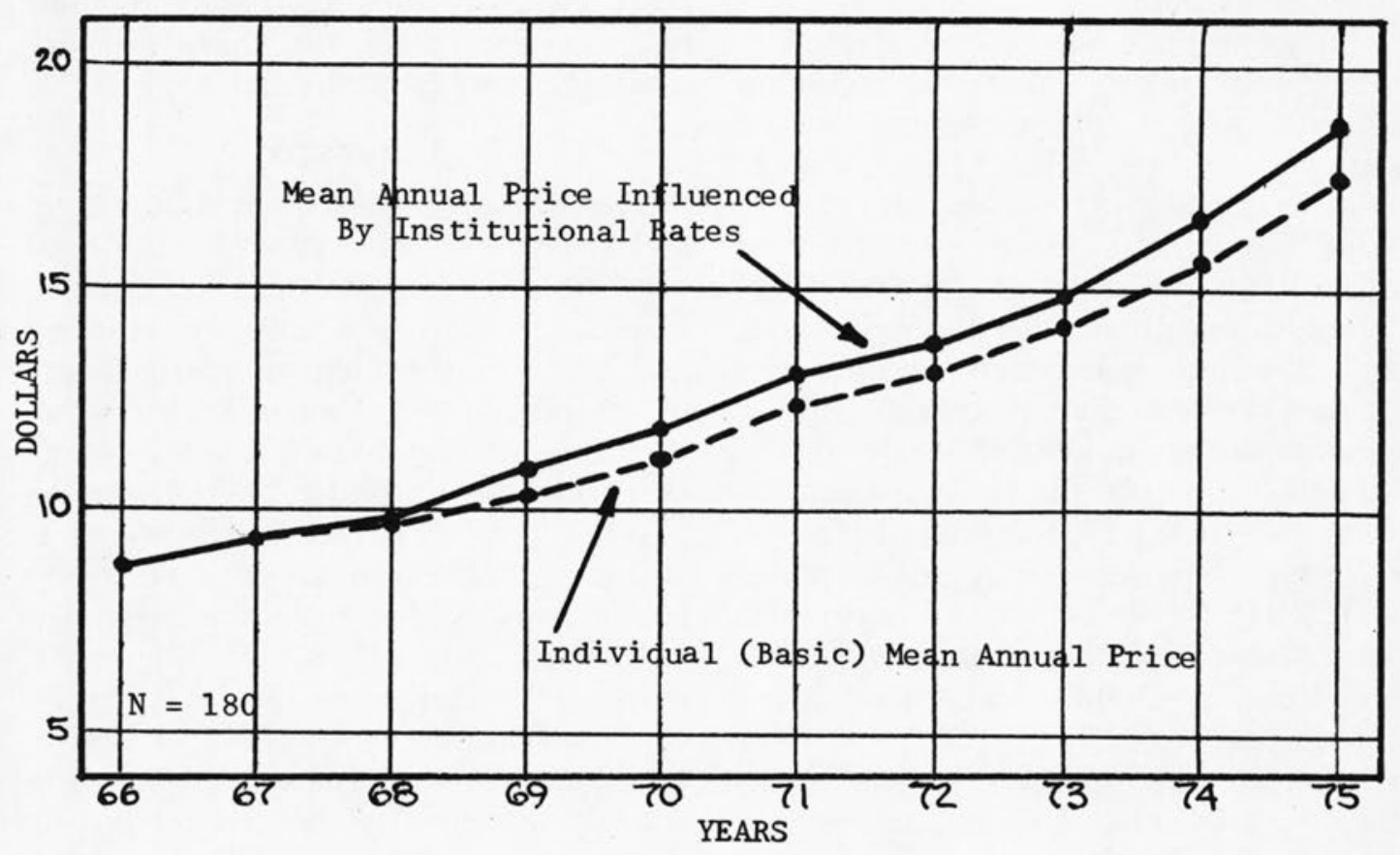

Fig. 1

Mean annual subscription rates for all periodicals

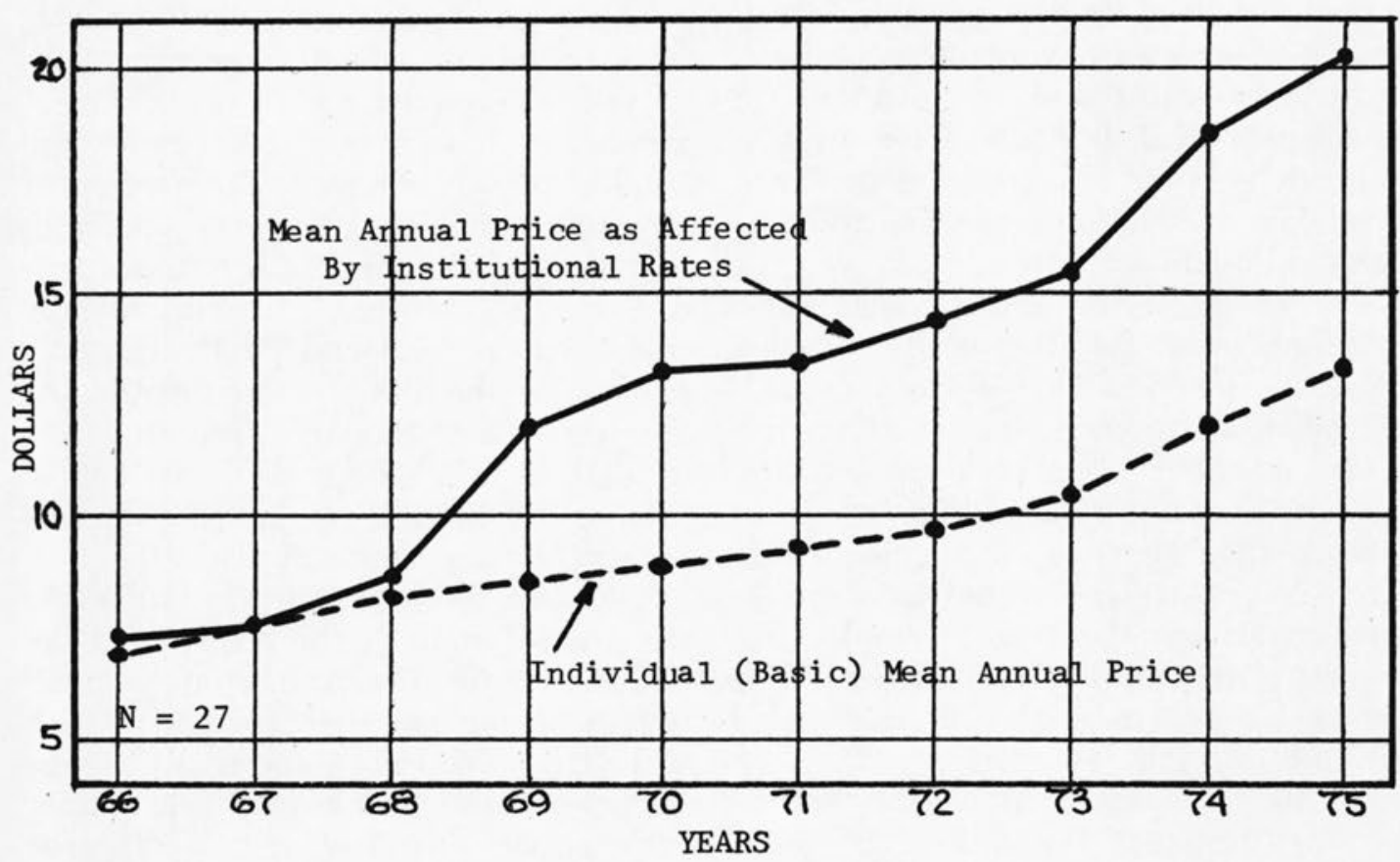

Fig. 2

Mean annual subscription rates for double-priced periodicals 
by a Mann-Whitney test on the data, of a growing disparity between the two subscription rates. The institutional rate is increasing at a higher average annual increment than is the average annual rate for individual subscriptions.

In other words, little by little though it may be now, libraries are being forced to bear the heavier share of cost increases. Thus as more periodicals shift to a two-tier subscription structure in the future, libraries will begin to experience even more obvious cost rises for periodical subscriptions. Inflation, then, will not be the only obvious culprit.

The characteristics of subscription rates are strange indeed, and they are surely complicated by the further complexities of dual pricing. For the most part the pattern is clear: a basic subscription rate (usually individual, or no stipulated distinction between any type subscriber) with-if any distinction is made by type of subscriber-a higher rate for libraries or institutions. But this is sometimes reversed or inverted where, for example, a "special rate to university libraries, faculty members, and students" amounted to a 50 percent reduction from a "general" subscription price. Or as was sometimes the case with art and architecture periodicals, the basic price was set for a wide range of individuals and institutions within the field; whereas a different price-sometimes higher, sometimes lower-was assessed to all those "outside the field." 3 In another case, the institutional rate began in 1966 lower than the individual rate, yet by 1975 it had become the greater of the two.

Why publishers have established double price structures has until recently remained largely a matter of conjecture. One long-suspected reason pertained to the combined issue of public-service photocopying and loss of individual issue sales. One publication board was even bold enough to put this in print as a reason for a forthcoming price increase to subscribers. Landscape Architecture in 1969 announced that "institutional subscribers (libraries, universities, research centers) will now have a seperate rate, made necessary by the xerographic revolution. The widespread use of facsimile reproduction in libraries, universities, etc. has reduced our singlecopy sales to students, teachers, researchers, etc. Many other publications already charge an institutional rate, as we now must to cover this aspect of technological change." 4

Whether this rationale held for the majority of other such publications is not known, although it would seem to bear considerable influence. Although dual pricing was in effect long before the recent Williams and Wilkins suit against the National Library of Medicine, it appeared to be at least one way for a publisher to recoup its conjectured losses from lack of sales.

Two seemingly contradictory results were reported in a recently completed study on the interaction between the publishers of scholarly and research journals in the United States and the libraries which form their primary customer base. ${ }^{5}$ One: "The statistics of this study indicate that the publisher's decision to charge libraries more than individuals is based on economic ... considerations." Two: Neither the general growth of interlibrary loan nor photocopying per se has adversely affected library periodical budgets. Still, in the final analysis, publishers argue "that librarians are singled out to shoulder increased prices because, despite their poverty, they are still the most affluent group of subscribers available."

It is difficult to determine the precise nature of the editorial board-publisherprinter relationships to any periodical; but in the case of the twenty-seven periodicals from this sample having a double price structure, the following can be said about them. Fifteen are either 
under the editorial sponsorship of a university (school, department, bureau, etc.) or are actually published by a university press. Twelve are sponsored or printed by independent-non-university-associations or presses. One of the latter happened to be from the Williams and Wilkins Company.

These results are likewise revealing in that universities and university presses are more predominant, although not by much, than the independent associations and presses. This immediately sheds a different light on the previous arguments regarding a rationale for dual pricing. Since university presses typically operate on a much tighter budget than do many non-university publishers, the question now becomes: Is the rationale for dual pricing solely an economic one? The limits to this study do not allow for an answer to that question.

About as many periodicals increased the number of issues published per year as cut back on the number of issues released. One title, Polymer Engineering and Science, not only advanced publication during the decade from four to twelve issues per year (volume) but switched to a two-tier subscription rate as well. In hindsight it is recognized that the number of issues published per year may well be only a very gross computation for a check on the effect of inflation. A more accurate picture would be obtained from a tally of the number of pages per volume. This, however, would be a tedious task indeed.

It is not possible to draw from this investigation any learned clues to explain why eight periodicals weathered the past decade without raising subscription rates. It can only be speculated that many, if indeed not all, receive heavy subsidization. If that be the case, more power to them and let the subscribers rejoice.

\section{REFERENCES}

1. Library Quarterly 46:359-77 (1976). See particularly "Pricing Strategies Which Discriminate against Libraries," p.364-66.

2. American National Standards Institute, Criteria for Price Indexes for Library Materials. ANSI Z39.20-1974 (New York: American National Standards Institute, 1974).

3. Example: "For those who are, by title, architects, engineers, architectural employees (specification writers, designers, draftsmen, estimators), planners or landscape architects, and to those in architectural education (students, faculty and schools), and to libraries, building construction trade associations, and building product manufacturers and their employees: basic rate $=\ldots$.

4. "Notice of Subscription Increase for Land- scape Architecture Quarterly," Landscape Architecture 59:258 (1969).

5. Bernard M. Fry and Herbert S. White, "Economics and Interaction of the PublisherLibrary Relationship in the Production and Use of Scholarly and Research Journals: Final Report," National Technical Information Service Report no. PB 249108 (Bloomington: Indiana Univ. Graduate Library School, 1975). The writer, however, has derived his information from the two journal papers written by White: the first, cited above as Reference 1, and "Library Management in the Tight Budget Seventies; Problems, Challenges, and Opportunities," Medical Library Association Bulletin 65:6-12 (1977). 